\title{
Quantitative Determination of Azithromycin in Human Plasma by Liquid Chromatography-Mass Spectrometry and its Application in Pharmackokinetic Study
}

\author{
Maizbha Uddin Ahmed, Mohammad Safiqul Islam, Tasmin Ara Sultana, A.G.M. \\ Mostofa, Muhammad Shahdaat Bin Sayeed, Zabun Nahar and Abul Hasnat
}

\author{
Department of Clinical Pharmacy and Pharmacology, University of Dhaka, Dhaka-1000, Bangladesh
}

\begin{abstract}
Azithromycin is an effective and well-known antimicrobial agent. In the present study, a simple, sensitive and specific LC/MS/MS method has been developed and validated for the quantification of Azithromycin in human serum samples using Clarithromycin as internal standard. Azithromycin was extracted from biological matrix by using solid phase extraction process. The chromatographic separation was performed on Luna $\mathrm{C} 18(3 \mu, 2 \times 150$ $\mathrm{mm}$ ) column with a mobile phase consisting of $35 \mathrm{mM}$ ammonium acetate buffer (mobile phase-A) and acetonitrile and methanol in ratio of 90:10 ( as mobile phase-B) at a flow rate of $0.25 \mathrm{~mL} / \mathrm{min}$. The method was validated over a linear concentration range of $0.5-50.0 \mathrm{ng} / \mathrm{mL}$ and limit of quantification (LOQ) was $0.5 \mathrm{ng} / \mathrm{mL}$ with a coefficient of correlation $\left(r^{2}\right)=0.9998$. The intra-day and inter-day precision expressed as relative standard deviation were $1.64 \%-$ $8.43 \%$ and $2.32 \%-9.92 \%$, respectively. The average recovery of azithromycin from serum was $98.11 \%$. The method was successfully applied to a pharmacokinetic study after oral administration of Azithromycin $200 \mathrm{mg} / 5 \mathrm{ml}$ suspension in healthy Bangladeshi volunteers.
\end{abstract}

Key words: Azithromycin, clarithromycin, method validation, pharmacokinetics, tandem mass spectrometry

\section{INTRODUCTION}

Azithromycin belongs to a new class of azalide antimicrobials is a semisynthetic derivative of erythromycin A. ${ }^{1}$ Azalide represents a group of ringexpanded derivatives of erythromycin A that contain an additional basic nitrogen at the 9a-position of the macrocyclic framework. ${ }^{2}$ Two sugar moieties are linked with the 15-membered macrocyclic lactone ring. It was developed from an interest in expanding the antimicrobial spectrum, improving the tolerability and the pharmacokinetic profile of the prototype macrolide antibiotic erythromycin A. For the treatment of upper and lower respiratory tract, skin and soft tissues, as well as sexually transmitted diseases azithromycin is now widely used. ${ }^{3,4}$ In oral

Correspondence to: Abul Hasnat

Fax: +880-2-8615583

E-mail: ahasnat99@yahoo.com

Dhaka Univ. J. Pharm. Sci. 11(1): 55-63, 2012 (June) dosage forms it is used as the dihydrate form and in parenteral dosage forms it is used as sodium salt. Azithromycin inhibits the transpeptidation/ translocation process by binding reversibly with $50 \mathrm{~S}$ component of 70S ribosomal subunit in the bacterial cell. As a result subsequent cell death occurs due to the premature detachment of incomplete peptide chains. $^{3,5}$

Azithromycin is either bactericidal or bacteriostatic, depending on the concentration of the molecule in vivo. Azithromycin can be used in the treatment of respiratory infections such as acute Streptococcus pyogenes pharyngitis, tonsillitis, otitis media, sinusitis, community-acquired pneumonia, acute bronchitis, acute exacerbations of chronic bronchitis and acute bacterial exacerbations of chronic obstructive pulmonary disease. ${ }^{6}$ It can also be used as an alternative antibiotic for patients that show penicillin sensitivity. In addition azithromycin can also be used for the treatment of skin and soft-tissue 
infections caused by some pathogens. ${ }^{3,4}$ The oral bioavailability of azithromycin was estimated to be $37 \%$ based on the area under plasma concentration time curve after administration of a single $500 \mathrm{mg}$ oral dose to healthy male volunteers where as the peak serum concentration occurred approximately of 0.4 to $0.45 \mu \mathrm{g} / \mathrm{ml}$ two hours after the dose..$^{6-9}$

Azithromycin is rapidly distributed to the tissues such as tonsils, prostate and gynaecological tissues, reaching high and sustained concentrations of up to 10-100 times greater than those found in serum following oral absorption. ${ }^{7}$ Most of the dose of azithromycin that is absorbed is not metabolized. ${ }^{10}$ The main pathway of metabolism is N-demethylation of the desosamine sugar to form N-desmethylazithromycin. Other pathways of metabolism include Odemethylation, deconjugation of the cladinose sugar and hydroxylation of the desosamine or aglycone ring. Azithromycin is largely excreted in the bile as unchanged drug and a small percentage appearing unchanged in the urine. . $^{3,710,11}$

Azithromycin lacks of specific chromophoric group and shows low sensitivity for UV detection in plasma. The published methods based on liquid chromatography using electrochemical detection. ${ }^{12-14}$ and fluorescence detection. ${ }^{15-18}$ Bioavailability of azithromycin was also studied by HPLC-APCI-MS and LC/MS/MS method. ${ }^{19,20}$ The aim of his study was to develop and validate a robust reversed-phase LC-MS-MS method for quantification of azithromycin in human plasma with very low LLOQ using a selective and sensitive Q TRAP MS system operated in MS-MS mode with an ESI interface and the application of this method to the pharmacokinetic study of azithromycin in Bangladeshi healthy volunteers. In the previously reported articles in maximum cases LLOQ is $5 \mathrm{ng} / \mathrm{mL}$ for azithromycin whereas our target is to develop the method to detect upto $0.5 \mathrm{ng} / \mathrm{mL}$ in human plasma that will be suitable for the pharmacokinetic study of azithromycin for longer duration (5-10 days). ${ }^{20}$

\section{MATERIALS AND METHODS}

Azithromycin and Clarithromycin (Internal Standard, IS) were kindly provided by Incepta Pharmaceuticals Ltd, Dhaka, Bangladesh. Acetonitrile, methanol and ammonium acetate were purchased from Fisher Scientific, UK. Other reagents used were of analytical grade. A Milli-Q ${ }^{\circledR}$ (Millipore, France) water purification system was used to obtain the purified water for the analysis.

Equipment. Azithromycin was analyzed by LC/MS/MS (3200 Q TRAP, Applied biosystem, Foster City, CA, USA). The system was controlled by Analyst 1.5 software.

LC System. The HPLC conditions were- Auto sampler \& Injection- Shimadzu prominence UFLC system, Equilibration time $=0.50 \mathrm{~min}$, Shimadzu LC system, Injection Volume $=20.00 \mu \mathrm{l}$, Rinsing Volume: $200 \mu \mathrm{l}$, Needle Stroke: $52 \mathrm{~mm}$, Rinsing Speed: $35 \mu 1 / \mathrm{sec}$, Sampling Speed: $15.0 \mu 1 / \mathrm{sec}$, Purge Time: $25.0 \mathrm{~min}$, Rinse Dip Time: $0 \mathrm{sec}$, Rinse Mode: before and after aspiration.

Pump conditions- Pumping Mode: Binary Flow, Total Flow: $0.2500 \mathrm{ml} / \mathrm{min}$, Pump B Pct: $0 \%$, B Curve: 0, Pressure Range (Pump A/B): $0.0-40.0$ $\mathrm{MPa}$, Total run time was $15 \mathrm{~min}$ and the running program was gradient where B pump was $98 \%$ at time 8 to $12 \mathrm{~min}$. Mobile phases in pump A was 35 $\mathrm{mM}$ ammonium acetate in water and pump B was mixture of $90 \%$ acetonitrile and $10 \%$ methanol. The column used was Luna C $18(3 \mu, 2 \times 150 \mathrm{~mm}$, Phenomenex, Torrance, CA, USA).

Mass spectrometric condition. Mass Spectrometer settings was- CUR: 20.00, CAD: Medium, IS 5500.00, TEM: 550.00, GS1: 45.00, GS2: 60.00, ihe: ON, CXP 4.00. The mass spectrometer operated in electro spray positive mode and data acquisition was in multiple reactions monitoring mode (MRM). Analyte concentrations in samples were calculated by comparing the ratio of an analyte base peak response to its appropriate internal standard response with the same ratio in calibration curve standards. MRM of the ions of azithromycin and were $748 \rightarrow 83.1$ for quantificantion and $748 \rightarrow$ 
151 for qualification whereas MRM of the ion of clarithromycin (IS) was $749 \rightarrow 158$ for quantification.

Sample processing. $0.1 \mathrm{ml}$ serum was taken in 7 $\mathrm{ml}$ vial and then $200 \mu \mathrm{l}$ Clarithromycin working solution $(10 \mathrm{ng} / \mathrm{ml}), 2.7 \mathrm{ml} 60 \mathrm{mM}$ sodium carbonate buffer ( $\mathrm{pH} \mathrm{11)} \mathrm{and} 2 \mathrm{ml}$ HPLC grade water were added. The mixture was vortexed for $20 \mathrm{~s}$ and loaded on to a bond elute $500 \mathrm{mg}, 3 \mathrm{ml}$ SPE phenyl cartridge (Varian, Harbor City, CA, USA), which had been conditioned by washing with methanol $(5 \mathrm{ml})$ followed by water $(5 \mathrm{ml})$. The cartridge was eluted with methanol $(5 \mathrm{ml})$. The elutant was evaporated to dryness using Techne Sample Concentrator (DB-3, Barloworld Scientific, Staffordshire, UK) at $40^{\circ} \mathrm{C}$ under a stream of nitrogen. Then, the dried extract was reconstituted in $1 \mathrm{ml}$ of mobile phase and was injected to the LC system with MS/MS detector.

Preparation of standard and quality-control solutions. A stock standard solution of azithromycin was prepared at the concentration of $500 \mu \mathrm{g} / \mathrm{ml}$ in methanol, and a stock standard solution of IS was prepared at the concentration of $100 \mu \mathrm{g} / \mathrm{mL}$ in methanol. Calibration standards were prepared by adding required amount of azithromycin stock solution and methanol, $200 \mu \mathrm{l}$ of IS solution (10 $\mathrm{ng} / \mathrm{ml}$ ) by spiking with blank serum (protein precipitated serum) to achieve the azithromycin concentration of 5, 10, 20, 25, 30, 40 and $50 \mathrm{ng} / \mathrm{ml}$. All standard samples were treated through SPE Phenyl cartridge as the method mentioned for sample processing. A calibration curve was constructed from a blank sample (a serum sample processed without an IS), a zero sample (a serum processed with IS) and seven non-zero samples covering the range 0.5-50 $\mathrm{ngmL}^{-1}$. The quality control (QC) samples were prepared in the same process using a different stock solution of Azithromycin, to obtain plasma concentrations of $0.5,5$ and $50 \mathrm{ng} / \mathrm{ml}$, representing low, medium and high concentration QC samples, respectively. All the samples were stored at $-80^{\circ} \mathrm{C}$.

Method validation. A variety of mobile phases were investigated in the development of a stability indicating LC method for the analysis of azithromycin and clarithromycin (IS) in serum. The suitability of mobile phase was decided based on selectivity and sensitivity of the assay, stability studies, separation and sharp peak among the methods during stability studies.

Lower limit of quantification (LLOQ). The LLOQ is the lowest amount of an analyte in a sample that can be quantitatively determined with suitable precision and accuracy (bias). ${ }^{21}$

Recovery and matrix effect. The analytical recovery of azithromycin was determined at concentrations of $0.5,5.0,50.0 \mathrm{ng} / \mathrm{ml}$. The extraction efficiency was determined by comparing peak areas of directly injected standards in the mobile phase and those from drug-free serum spiked with standards and submitted to the sample preparation and extraction procedures $(n=6)$. The recovery of clarithromycin (internal standard) was also determined using the similar process.

Stability. The stability of the analyte is often critical in biological samples even over a short period of time. Degradation is not unusual even when all precautions are taken to avoid specifically known stability problems of the analyte (e.g. light sensitivity). It is therefore important to verify that there is no sample degradation between the time of collection of the sample and their analysis that would compromise the result of the study. Stability evaluation is done to show that the concentration of analyte at the time of analysis corresponds to the concentration of the analyte at the time of sampling. ${ }^{22}$

Selectivity (specificity). Studies are designed to evaluate the degree of performance of interference, if any, which can be attributed to other analytes, impurities and degradation products, reagents "blanks" and excipients. It is also known as selectivity. ${ }^{23}$ In the Conference Report II, selectivity was defined as follows: Selectivity is the ability of the bioanalytical method to measure unequivocally and to differentiate the analyte(s) in the presence of components, which may be expected to be present. Typically, these might include metabolites, impurities, degradants, matrix components, etc. ${ }^{24}$ 
Linearity. For HPLC methods the relationship of the sample concentration and detector response (peak area and height) are used to make this determination. $^{23}$ For linearity relationship a calibration curve is to be drawn. It is necessary to use a sufficient number of standards to define adequately the relationship between response and concentration. The relationship between response and concentration must be demonstrated to be continuous and reproducible.

Accuracy and precision. Accuracy studies are usually evaluated by determining the recovery of the spiked sample of the analyte into the matrix of the sample to be analyzed. ${ }^{23}$ Accuracy together with precision is set to determine the error associated with an analytical method and they are therefore important criteria for the evaluation of the suitability of an analytical method for the task for which it is intended. ${ }^{25}$ The accuracy of a method is affected by systematic (bias) as well as random (precision) error components. ${ }^{22,26}$ This fact has been taken into account in the definition of accuracy as established by the International Organization for Standardization. ${ }^{27}$ However, it must be mentioned, that accuracy is often used to describe only the systematic error component, i.e. in the sense of bias. ${ }^{21,22,24,28-31}$ In the following, the term accuracy will be used in the sense of bias, which will be indicated in brackets.

\section{Pharmacokinetic study}

Volunteers. Twelve healthy male Bangladeshi volunteers were enrolled in this study with mean (SD) age, 21.42 (0.90) years (range $20-23$ years); mean (SD) body weight, 71.50 (11.41) kg (range 51 $90 \mathrm{~kg}$ ); mean (SD) height, 1.73 (0.06) m (range 1.63 $-1.80 \mathrm{~m}$ ) and mean (SD) body mass index (BMI), $23.65(2.58) \mathrm{kg} / \mathrm{m}^{2}$ (range $19.30-28.47 \mathrm{~kg} / \mathrm{m}^{2}$ ). All the volunteers completed the study without any adverse effects.

Inclusion and exclusion criteria. All volunteers were examined to verify their health status; these examinations included medical history, vital sign measurements, electrocardiography (ECG), blood sample analysis (basic profile, complete blood cell count, bleeding time, clotting time, prothrombin time, viral serology), and urinalysis (sediment, drugs). Volunteers with relevant clinical, analytical, or ECG abnormalities were excluded from the trial. Additional exclusion criteria were as follows: smoking; history of alcohol or other drug abuse; consumption of any medication within one month prior to study commencement, participation in a clinical trial in the 4 months before enrolment; history of clinically important illness or major surgery in the 6 months before enrolment; inability to relate to and/or cooperate with the investigators; medication allergy; illnesses or disorders that could affect the absorption, distribution, metabolism, and/or excretion of drugs (e.g., malabsorption, oedemas, renal and/or hepatic failure); a history of positive serology for hepatitis $\mathrm{B}$ or $\mathrm{C}$ (not due to immunization) or HIV; blood loss or donation in the 3 months before enrolment; blood or blood-derivative transfusion in the 6 months before enrolment; and exhausting physical exercise in the 72 hours before enrolment. All eligible volunteers provided written informed consent to participate and were free to withdraw from the study at any time without any obligation.

Study design. The study was conducted in the Department of Clinical Pharmacy and Pharmacology, Faculty of Pharmacy, University of Dhaka in association with a well-equipped private hospital in Dhaka, Bangladesh in accordance with the International Conference of Harmonization (ICH) guidelines for Good Clinical Practice (GCP) and in compliance with the Declaration of Helsinki and its amendments. ${ }^{32,33}$ Ethical approval for this study was taken from the Bangladesh Medical Research Council (BMRC). The study was a single-dose, randomized, open-label, one-period study. A single dose of Azithromycin $200 \mathrm{mg} / 5 \mathrm{ml}$ powder for suspension formulation (Tridosil ${ }^{\circledR} 200 \mathrm{mg} / 5 \mathrm{ml}$ suspension, Incepta Pharmaceuticals Ltd, Bangladesh.) was administered with $250 \mathrm{~mL}$ of water after an overnight fast. A standardized breakfast and lunch were given at 4 and 8 hours after drug administration, respectively. During the study period, the volunteers were under medical surveillance to report any adverse events. 
Blood sampling. A $20-\mathrm{G} \times 1.25$-inch catheter (Vasofix ${ }^{\circledR}$ Braunüle ${ }^{\circledR}$, B. Braun Melsungen AG, Melsungen, Germany) was inserted into a suitable forearm vein and $3 \mathrm{ml}$ of blood was withdrawn in each time of collection. Blood samples ( $3 \mathrm{ml}$ each) were collected prior to dosing $(0 \mathrm{~h})$ and at $0.5,1.0$, 1.5, 2.0, 3.0, 4.0, 6.0, 8.0, 10.0, 12.0, 24.0, 48.0, 72.0, 96.0 and $120.0 \mathrm{hr}$ following dosing. The blood samples were kept for 30 minutes at ambient temperature in a dark place and then centrifuged at $1500 \mathrm{rpm}$ for 15 minutes at room temperature to separate serum and stored at $-80^{\circ} \mathrm{C}$ until assayed for Azithromycin content.

Pharmacokinetics and statistical analysis. Pharmacokinetic properties of Azithromycin were calculated by a non-compartmental approach from serum concentrations of Azithromycin using software Kinetica (Version 4.4.1, Thermo Electron Corporation, UK). $\mathrm{C}_{\max }$ was estimated directly from observed concentrations, and $\mathrm{T}_{\max }$ as the corresponding time point at which $\mathrm{C}_{\max }$ occurred. $\mathrm{AUC}_{0-\mathrm{t}}$ was calculated by the linear trapezoidal method until the last measurable serum drug concentration, and $\mathrm{AUC}_{0-8}$ was calculated as $\mathrm{AUC}_{0-8}$ $=\mathrm{AUC}_{0-\mathrm{t}}+\mathrm{C}_{\text {last }} / \mathrm{K}_{\mathrm{el}} \cdot \mathrm{k}_{\mathrm{el}}$ was the terminal elimination rate constant calculated by linear least square regression of the last three to four time points in the $\log$ concentration time profile and the terminal halflife was calculated by the following equation $: t_{1 / 2}=$ $0.693 / k_{e l}$.

\section{RESULT AND DISCUSSION}

Performance of MS-MS or Mass spectrometry. The electrospray interface was used to obtain good sensitivity, fragmentation, and linearity. We tested atmospheric pressure ionization (APCI) and no obvious improvement was observed. The first step in developing the detection method was to select the precursor ion to be fragmented. Azithromycin and the internal standard were monitored in positive ion mode because of its high signal intensity. The protonated molecule $[\mathrm{M}+\mathrm{H}]+$ was the most intense and was therefore chosen as the precursor ion for the determination. Capillary, cone, extractor, and RF voltages were optimized to obtain the maximum signal intensity of $[\mathrm{M}+\mathrm{H}]^{+}$ion. The product ion spectra of Azithromycin and internal standard were obtained after optimization. Collision energy was optimized with regard to the intensity of the selected product ions.

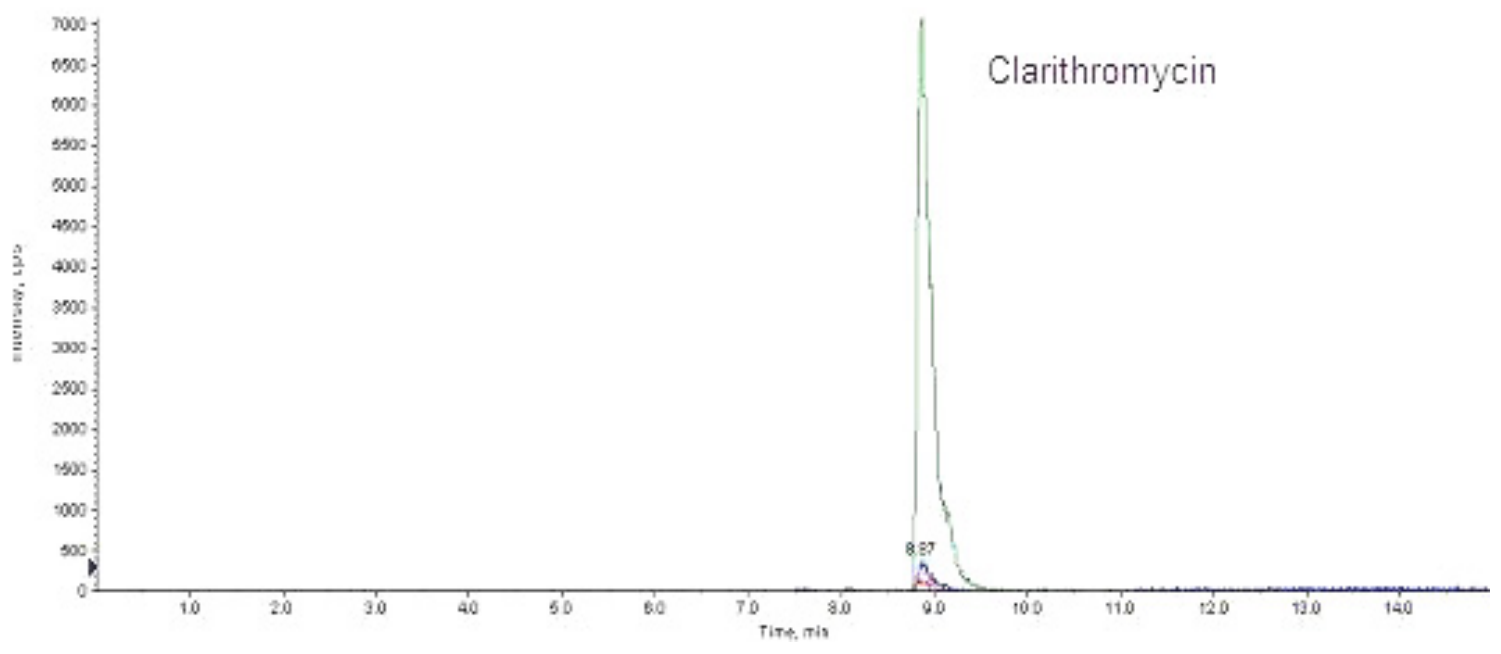

Figure: 1 a). MRM chromatogram obtained from blank serum spiked with Clarithromycin 


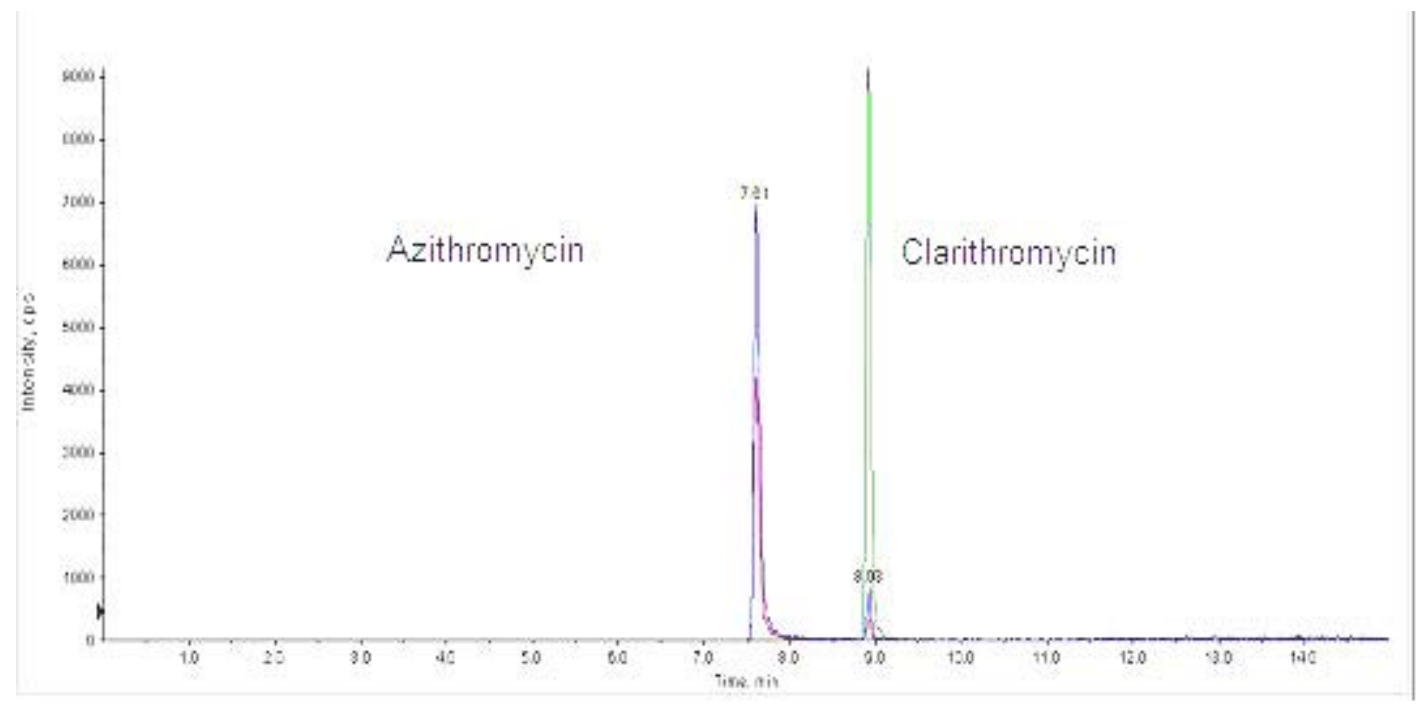

Figure: $1 \mathrm{~b}$ ). MRM chromatogram of Azithromycin spiked with Clarithromycin (Internal Standard).

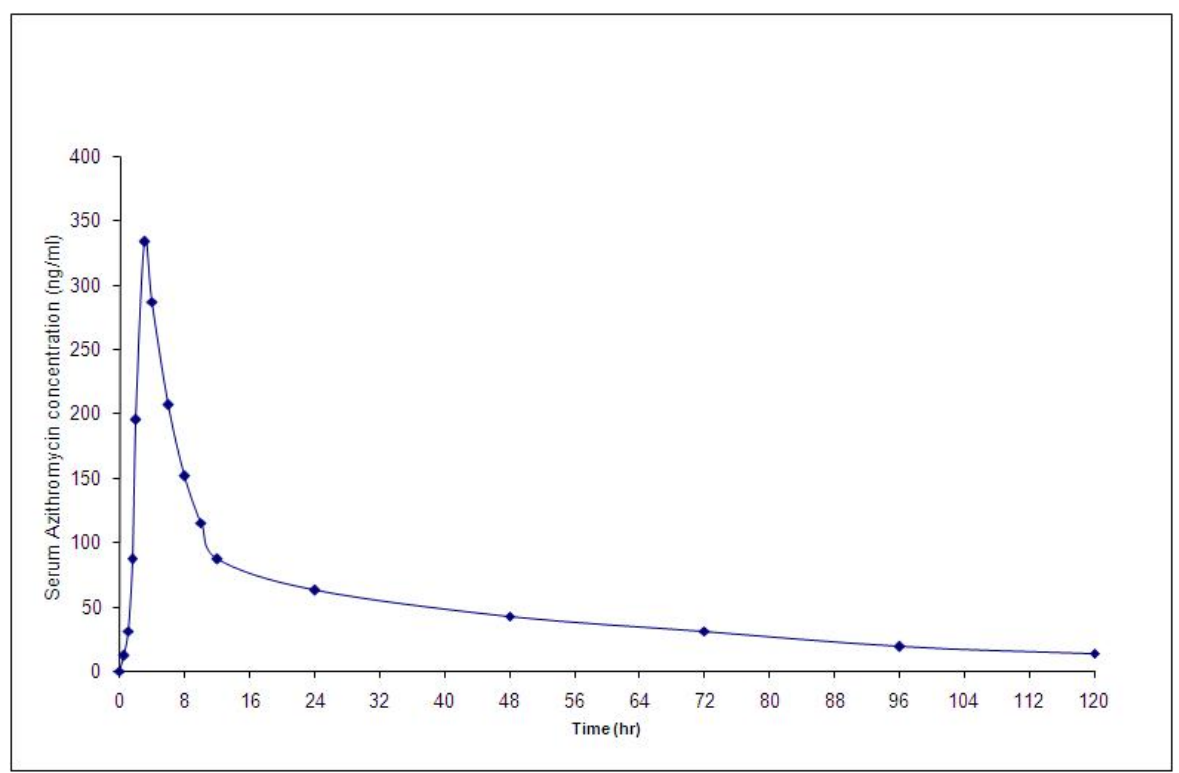

Figure 2. Mean Azithromycin concentration-versus-time curve over 120 hours in adult healthy Bangladeshi volunteers $(\mathrm{N}=12)$.

Performance of LC or Selection of HPLC column and mobile phase. Azithromycin is a lipophilic compound, with basic character, which is well adsorbed on hydrophobic sorbents. The Luna C18, $(2 \times 150) \mathrm{mm}, 3 \mu$ column was used to obtain maximum response to azithromycin and reasonable analysis time. Symmetrical peak shapes for azithromycin and clarithromycin could be easily obtained on $\mathrm{C} 18$, because of the highly lipophilic character and strong adsorption of azithromycin on the column material. The Luna $\mathrm{C} 18,(2 \times 150) \mathrm{mm}, 3$ $\mu$ was eventually selected for all assays because it gave excellent peak shape and resulted in the highest response to azithromycin.

Selection of mobile phase components was also critical factor. Because phosphate buffer cannot be used with MS, we employed ammonium acetate to supply the ionic strength. Increasing the percentage of buffer in the mobile phase enhanced analyte peak symmetry and resolution but simultaneously 
prolonged the retention time of the internal standard. Finally, a three-component mobile phase containing methanol, acetonitrile, and buffer was used with satisfactory results.

\section{Validation of the Azithromycin assay}

Specificity and selectivity. The method exhibited good specificity and selectivity. The selectivity of the method assessed by comparing chromatograms of a blank serum, treated volunteer's serum sample spiked with internal standard. The retention times were $7.62 \mathrm{~min}$ and $8.94 \mathrm{~min}$ for Azithromycin and Clarithromycin, respectively. As shown in the Figure 3, there were no interfering peaks from endogenous substances at the elution time of azithromycin and clarithromycin.

Recovery and matrix effect. The extraction recoveries of azithromycin determined at three different concentrations $(0.5,5.0$ and $50.0 \mathrm{ng} / \mathrm{ml})$. The method showed good efficiency in terms of recovery as the average recovery for Azithromycin was 98.11 $\%$ and that of Clarithromycin was $94.0 \%$. Solid phase extraction using methanol and water was simpler and faster than other methods reported previously.

Linearity, accuracy, and precision. All calibration curves were linear over the concentration range of $0.5-50.0 \mathrm{ng} / \mathrm{ml}$, with an average coefficient of correlation $\left(\mathrm{r}^{2}\right)=0.9998$.

The intra-day precision (expressed as the $\% \mathrm{CV}$ for QC samples of $0.50,5.0,50.0 \mathrm{ng} / \mathrm{ml}$ ) was in the range of $1.64 \%$ to $8.43 \%$ and inter-day precision was $2.32 \%$ to $9.92 \%$. The accuracy was in the range of $95.20 \%$ to $105.47 \%$ (Table 1 ).

Table 1. Intra-day and Inter-day precision and accuracy of Azithromycin in serum

\begin{tabular}{|c|c|c|c|}
\hline \multirow{3}{*}{ Reading no. } & \multicolumn{3}{|c|}{ Intra-day precision and accuracy $(\mathrm{n}=6$ replicate $)$} \\
\hline & \multicolumn{3}{|c|}{ Declared conc. (ng/ml) } \\
\hline & $0.5(\mathrm{ng} / \mathrm{ml})$ & $5.0(\mathrm{ng} / \mathrm{ml})$ & $50.0(\mathrm{ng} / \mathrm{ml})$ \\
\hline & \multicolumn{3}{|c|}{ Calculated concentration $(\mathrm{ng} / \mathrm{ml})$} \\
\hline 1 & 0.53 & 5.1 & 48.7 \\
\hline 2 & 0.50 & 4.6 & 48.1 \\
\hline 3 & 0.57 & 4.9 & 46.9 \\
\hline 4 & 0.51 & 5.3 & 48.2 \\
\hline 5 & 0.52 & 4.8 & 47.4 \\
\hline 6 & 0.54 & 5.8 & 49.0 \\
\hline Mean (SD) & $\begin{array}{c}0.53 \\
(0.0259)\end{array}$ & $\begin{array}{c}5.08 \\
(0.4280)\end{array}$ & $48.050 .7868)$ \\
\hline Accuracy $(\%)$ & 105.47 & 101.60 & 96.10 \\
\hline $\mathrm{CV}(\%)$ & 4.90 & 8.43 & 1.64 \\
\hline \multicolumn{4}{|c|}{ Inter-day precision and accuracy $(\mathrm{n}=6$ replicate $)$} \\
\hline \multirow{2}{*}{ Reading no. } & \multicolumn{3}{|c|}{ Declared conc. $(\mathrm{ng} / \mathrm{ml})$} \\
\hline & $0.5(\mathrm{ng} / \mathrm{ml})$ & $5.0(\mathrm{ng} / \mathrm{ml})$ & $50.0(\mathrm{ng} / \mathrm{ml})$ \\
\hline & \multicolumn{3}{|c|}{ Calculated concentration (ng/ml) } \\
\hline 1 & 0.48 & 4.7 & 49.0 \\
\hline 2 & 0.57 & 5.1 & 47.6 \\
\hline 3 & 0.42 & 4.9 & 48.1 \\
\hline 4 & 0.48 & 4.5 & 46.8 \\
\hline 5 & 0.49 & 4.7 & 45.9 \\
\hline 6 & 0.51 & 5.7 & 48.2 \\
\hline
\end{tabular}

Stability. The stabilities of Azithromycin in serum at $-80^{\circ} \mathrm{C}$ for 1 month, after three freeze-thaw cycles and at room temperature for $6 \mathrm{~h}$ as well as at $80^{\circ} \mathrm{C}$ for $48 \mathrm{~h}$ after preparation are presented in table
2. It was clear that azithromycin was stable at both high and low concentrations under all tested storage conditions and time. 
Pharmacokinetic study. The mean serum concentration-time profile of azithromycin has been shown in Figure. The mean $\mathrm{C}_{\max }$ was found to be $413.32 \pm 13.29 \mathrm{ng} / \mathrm{ml}$ occurring at $\mathrm{T}_{\max }$ of $3.08 \mathrm{hr}$ \pm 0.67 . The $\mathrm{AUC}_{0-120}$ and $\mathrm{AUC}_{0-8}$ values were
$6138.61 \pm 1189.29 \mathrm{hr}-\mathrm{ng} / \mathrm{ml}$ and $6580.83 \pm 1263.82 \mathrm{hr}-$ $\mathrm{ng} / \mathrm{ml}$ respectively. Elimination rate constant calculated for azithromycin was $0.022 \pm 0.0015 \mathrm{hr}^{-1}$ with the elimination half-life of $32.90 \pm 2.32 \mathrm{hr}$

Table 2. Stability of azithromycin in human serum

\begin{tabular}{clcc}
\hline $\begin{array}{c}\text { Declared } \\
\text { conc. }(\mathrm{ng} / \mathrm{ml})\end{array}$ & \multicolumn{1}{c}{ Conditions } & $\begin{array}{c}\text { Conc. in serum } \\
(\mathrm{ng} / \mathrm{ml})\end{array}$ & Recovery in serum $(\%)$ \\
\hline 0.5 & After 6 hr at ambient temp. & 0.495 & 99.00 \\
& 48 hr storage at $-80^{0} \mathrm{C}$ & 0.49 & 98.00 \\
& Three freeze-thaw cycles & 0.486 & 97.10 \\
& 1 month storage at $-80^{0} \mathrm{C}$ & 0.484 & 96.80 \\
5 & After 6 hr at ambient temp. & 4.98 & 99.60 \\
& 48 hr storage at $-80^{0} \mathrm{C}$ & 4.95 & 99.00 \\
& Three freeze-thaw cycles & 4.925 & 98.50 \\
& 1 month storage at $-80^{0} \mathrm{C}$ & 4.895 & 97.90 \\
& After 6 hr at ambient temp. & 49.80 & 99.60 \\
& 48 hr storage at $-80^{0} \mathrm{C}$ & 49.30 & 98.60 \\
& Three freeze-thaw cycles & 49.25 & 98.50 \\
& 1 month storage at $-80^{0} \mathrm{C}$ & 48.35 & 96.70 \\
\hline
\end{tabular}

\section{CONCLUSION}

The present LC/MS/MS method was simple, rapid, accurate, precise, reproducible, and selective enough to allow the analysis of azithromycin in human serum samples after single oral dose of azithromycin $200 \mathrm{mg} / 5 \mathrm{ml}$ powder for suspension which fulfils the acceptance criteria generally established for bioanalytical assays. The extraction process used was very easy and rapid. The method was successfully applied for the determination of pharmacokinetic parameters of azithromycin in healthy Bangladeshi male volunteers.

\section{REFERENCES}

1. Wilson and Gisvold's textbook of organic medicinal and pharmaceutical chemistry. 2004. 11th ed. Block, J.H., Beale, J.M. Lippincot Williams and Wilkins. London, p. 352.

2. Kujundžič, N., Kobrehel, G., Banič, Z., Kelnerić, Ž. and Koić-Prodić, B. 1995. Azalides: synthesis and antibacterial activity of novel 9a-N-(N'-Substituted Carbamoyl and Thiocarbamoyl) derivatives of 9-deoxo-9a-aza-9ahomoerythromycin A. Eur. J. Med. Chem. 30, 455-462.

3. Hoepelman, M.I. and Schneider E.M.M. 1995. Azithromycin: The first of the tissue-selective azalides. Int. J. Antimicrob. Agents. 5, 145-167.

4. Harold, C. Clinical microbiology of azithromycin. 1991. Am. J. Med. 91, S12-S18.
5. Retsema, J. and Wench, F. 2001. Macrolides: Structure and microbial targets. Int. J. Antimicrob Agents. 18, S3-S10.

6. Drew, H.R. and Gallis, A.H. 1992. Azithromycin-spectrum of activity. Pharmacokinetics and Clinical Applications. Pharmacotherapy. 12, 161-173.

7. Foulds, G., Shepard, R.M. and Johnson, R.B. 1990. The pharmacokinetics of azithromycin in human serum and tissue. J. Antimicrob. Chemother. 25, 73-82.

8. Peters, D.H., Friedel, H.A. and McTavish, D. 1992. Azithromycin: A review of its antimicrobial activity, pharmacokinetic properties and clinical efficacy. Drugs 44, 750-799.

9. Rapp, R.P. 1998. Pharmacokinetics and pharmacodynamics of Intravenous and oral Azithromycin: Enhanced tissue activity and minimal drug interactions. Ann. Pharmacother. 32, 785-793.

10. Lalak, N.J. and Morris, D.L. 1993. Azithromycin clinical pharmacokinetics. Clin. Pharmacokinet. 25, 370-374.

11. The complete drug reference. 2002. 33rd ed. Martindale: Pharmaceutical Press (PhP), London, p153.

12. Kees, F., Spangler, S. and Wellenhofer, M. 1998. Determination of macrolides in biological matrices by highperformance liquid chromatography with electrochemical detection. J. Chromatogr A. 812, 287-293.

13. Gandhi, R., Kaul, C.L. and Panchagnula, R. 2000. Validated LC method for in-vitro analysis of azithromycin using electrochemical detection. J. Pharm. Biomed. Anal. 23, 10731078. 
14. Taninaka, C., Ohtani, H., Hanada, E., Kotaki, H., Sato, H. and Iga, T. 2000. Determination of erythromycin, clarithromycin, roxithromycin, and azithromycin in plasma by high-performance liquid chromatography with amperometric detection. J. Chromatogr B. 738, 405-411.

15. Torano, J.S. and Guchelaar, H.J. 1998. Quantitative determination of the macrolide antibiotics erythromycin, roxithromycin, azithromycin and clarithromycin in human serum by high-performance liquid chromatography using pre-column derivatization with 9- fluorenylmethyloxycarbonyl chloride and fluorescence detection. J. Chromatogr. B. 720, 89-97.

16. Bahrami, B.G., Mirzaeei, S. and Kiani, A. 2005. High performance liquid chromatographic determination of azithromycin in serum using fluorescence detection and its application in human pharmacokinetic studies. $J$. Chromatogr. B. 820, 277-281.

17. Wilms, E., Trumpie, H., Veenendaal, W., and Touw, D. 2005. Quantitative determination of azithromycin in plasma, blood and isolated neutrophils by liquid chromatography using pre-column derivatization with 9-fluorenylmethyloxycarbonyl-chloride and fluorescence detection. $J$. Chromatogr. B. 814, 37-42.

18. Bahrami, G. and Mohammadi, A. 2006. A new on-line, intube pre-column derivatization technique for high performance liquid chromatographic determination of azithromycin in human serum. J. Chromatogr. B. 830, 355358.

19. Barrett, B., Borek-Dohalsky, V., Fejt, P., Vaingatova, S., Huclova, J., Nemec, B. and Jelinek, I. 2005. Validated HPLC-MS-MS method for determination of azithromycin in human plasma. Anal. Bioanal. Chem. 383, 210-217.

20. Nirogi, R.V.S., Kandikere, V.N., Shukla, M., Mudigonda, K., Maurya, S., Boosi, R. and Yerramilli, A. 2005. Sensitive and selective liquid chromatography-tandem mass spectrometry method for the quantification of azithromycin in human plasma. Anal. Chim. Acta. 553, 1-8.

21. ICH Q2 A. 1994. Validation of Analytical Methods: Definitions and Terminology. International Conference on Harmonization (ICH).

22. Hartmann, C., Smeyers-Verbeke, J., Massart, D.L. and McDowall, R.D. 1998. Validation of bioanalytical chromatographic methods. J. Pharm. Biomed. Anal. 17, 193218.

23. Hand Book of Pharmaceutical Analysis by HPLC. 2005. $6^{\text {th }}$ ed. Ahuja, S. and Michael, W.D. Elsevier academic press, Amsterdam. pp.197-206.
24. Shah, V.P., Midha, K.K., Dighe, S., McGilveray, I.J., Skelly, J.P., Yacobi, A., Layloff, T., Viswanathan, C.T., Cook, C.E., McDowall, R.D., Pittman, K.A. and Spector, S. 1992. Analytical methods validation: bioavailability, bioequivalence and pharmacokinetic studies. Conference report. Pharm. Res. 9, 588-592.

25. Rosing, H., Man, W.Y., Doyle, E., Bult, A. and Beijnen, H.J. 2000. Bioanalytical liquid chromatographic method validation. A review of current practices and procedures. $J$. Liq. Chromatogr. Relat. Technol. 23, 329-354.

26. Hartmann, C., Massart, D.L. and McDowall, R.D. 1994. An analysis of the Washington Conference Report on bioanalytical method validation. J. Pharm. Biomed. Anal. 12, 1337-1343

27. Accuracy (Trueness and Precision) of Measurement Methods and Results. International Organization for Standardization. ISO/DIS 5725-1 to 5725-3. 1994.

28. Bressolle, F., Bromet, P.M., Audran, M. 1996. Validation of liquid chromatographic and gas chromatographic methods. Applications to pharmacokinetics. J. Chromatogr. B. 686, 310.

29. Causon, R. 1997. Validation of chromatographic methods in biomedical analysis: Viewpoint and discussion. $J$. Chromatogr. B. 689, 175-180.

30. Karnes, H.T., Shiu, G. and Shah, V.P. 1991. Validation of bioanalytical methods. Pharm. Res. 8, 421-426.

31. Wieling, J., Hendriks, G., Tamminga, W.J., Hempenius, J., Mensink, C.K., Oosterhuis, B. and Jonkman, J.H. 1996. Rational experimental design for bioanalytical methods validation. Illustration using an assay method for total captopril in plasma. J. Chromatogr. A. 730, 381-394.

32. European Agency for the Evaluation of Medicinal Products, International Conference on Harmonization - World Health Organization. 2002. Guideline for Good Clinical Practice. ICH topic E6. Geneva, Switzerland: WHO. http://www.emea. europa.eu Accessed January 12, 2012.

33. World Medical Association Declaration of Helsinki: Ethical Principles for Medical Research Involving Human Subjects. 2000. Adopted by the 18th WMA General Assembly, Helsinki, Finland, June 1964, and amended by the 52nd WMA General Assembly, Edinburgh, Scotland. http://www. wma.net/e/policy/b3.htm Accessed Dec 15, 2011 